\title{
Entre filosofía y literatura en torno a Henry James Álvaro Peláez y Zenia Yébenes (coords.)
}

Iraia Elordy Alverde

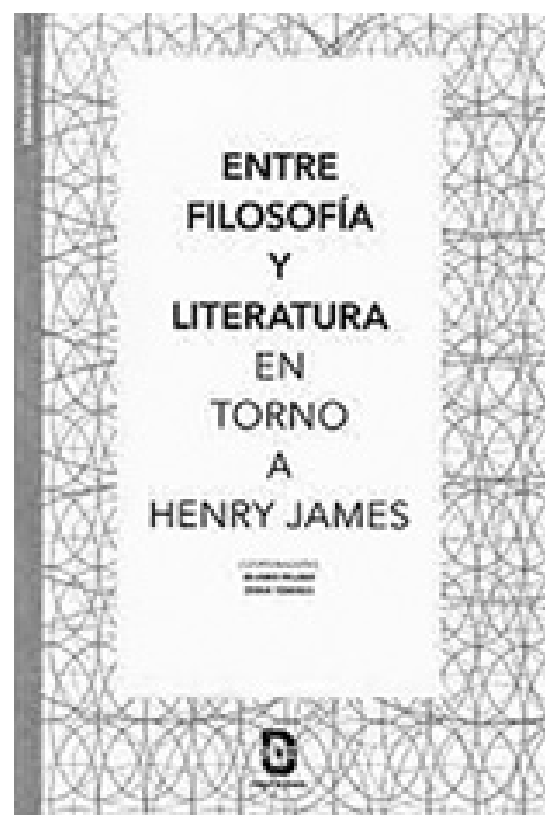

Álvaro Peláez y Zenia Yéhenes (coordinadores). Entre filosofía y literatura en torno a Henry James. Ciudad de México; uam Cuajimalpa, 2018.
Las relaciones interpersonales se sostienen bajo supuestos contextuales que buscamos mantener con el propósito de encontrar nuestro lugar en la sociedad. Esto implica conceptos morales asumidos como universales, la constante interpretación de acciones y una ambigüedad epistemológica presente en toda toma de decisiones. Para Henry James, el valor de una novela recae en la capacidad que tiene de representar la vida, haciendo énfasis en la exposición de situaciones comunes para que el lector se identifique, pero, al mismo tiempo, lo suficientemente paradójicas como para no reconocer dicha relación. Esto involucra la forma en que se apela a la moral para justificar las acciones e intenciones, con el propósito de conse- 
guir algo en beneficio propio, así como la manera en que se adoptan nociones, juicios y secretos como modo de supervivencia. La ambigüedad utilizada por James es el elemento que da pie a un sinfín de interpretaciones de sus obras y a una búsqueda constante para adecuarlas al infinito juego de posibilidades dentro de la realidad que cada quien experimenta.

Entre filosofía y literatura en torno a Henry James, coordinado por Álvaro Peláez y Zenia Yébenes, es la recapitulación de seis artículos que exponen, desde el análisis de varias obras de James, las diferentes maneras en que se presenta y utiliza la moral en las relaciones interpersonales de sus personajes, y los efectos a partir de su uso. Desde el cuestionamiento de la maldad en los infantes hasta la capacidad de reflexión de los adultos, este texto muestra la transición que experimentan los nińos y adultos en su búsqueda por reconocimiento y autonomía, desde la moral moderna. Sin adentrarse por completo en los textos de James, este libro busca resaltar filosóficamente el conjunto de elementos que conforman una sociedad a partir de contextos específicos. Algunos de ellos son: a) los problemas a los que se enfrentan los niños, quienes contemplan en las acciones de los adultos a su alrededor la manera de adentrarse en el mundo para ser reconocidos y $b$ ) los dilemas de los adultos como consecuencia de sus decisiones egoístas.

Más allá del tema de cada artículo, se presentan en ese orden con la intención de formar una secuencia que permita al lector adentrarse en una trama común: cómo se pierde la inocencia al buscar autonomía y cuál es el resultado moral de ello en la vida adulta. La problemática principal en todos los casos es: ¿cómo se puede conocer y tener mente propia?

Los primeros dos artículos, "Sobre el conocimiento de Maisie de su propia mente de Robert Pippin" y " $\mathrm{La}$ inocencia perdida: psicología infantil y adolescente en la narrativa tardía de Henry James" de Xavier de Donato Rodríguez, dan a conocer desde un análisis de Lo que Maisie sabia, El alumno y Otra vuelta de tuerca: el proceso psicológico por el cual pasan tres niños para emanciparse de la moral establecida en su entorno y tener la posibilidad de ejercer su libertad. En ambos textos se relacionan la 
ambigüedad —característica primordial en las novelas de James- con la capacidad de identificar y reidentificar lo que uno piensa por sí mismo y lo que le han dicho que debe pensar. Pese a que podría suponerse que ambas características son ajenas, es la ambigüedad en las obras de James lo que permite la multiplicidad de perspectivas dentro de un mismo relato; expone lo complejo que es crear y tener mente propia, y conocer si se decide o no por intereses ajenos o propios.

En el tercer artículo "La novela, la filosofía y el valor”, Álvaro Peláez Cedrés comienza a indagar con mayor detalle en la importancia que James da al valor y a la moral. Si entendemos la novela como un relato de vida, su valor radica en la confirmación de que toda experiencia está conformada por el enfrentamiento y la coexistencia de los polos morales. En "Las alas de la paloma: cierta lectura kantiana”, Zenia Yébenes se adentra en la problemática moral y la paradoja de decisión, desde el sistema espacio-temporal kantiano; explica que nadie puede salirse del sistema de representación en el cual se encuentra y verificar si hay ética en la suma de sus actos. ${ }^{1}$

En las novelas de James apenas se percibe el principio moral vacío que obliga a los personajes a responsabilizarse de sus actos, para postular ante los demás una ética concreta a seguir, y así, ir creando cultura. Carlos Mendiola Mejía propone que la ética sólo le es visible al ser humano en retrospectiva y en conjunto, en su texto "La paradoja de la comprensión en La copa dorada de Henry James"; queda más claro que la comprensión y atención, con las cuales se interpretan las acciones ajenas, siempre tienen grietas. El ser humano únicamente puede tener una mejor interpretación cuando reflexiona sobre una situación específica. A partir del análisis de $L a$ copa dorada, Carlos Mendiola da a conocer que todos estamos limitados por aquello que ignoramos y se encuentra fuera de nuestro margen de representación: "Toda atención implica una

\footnotetext{
Yébenes detalla que, dentro de su artículo, no hay una distinción conceptual entre moral y ética. Zenia Yébenes Escardó, "Las alas de la paloma: cierta lectura kantiana” en Entre filosofía y literatura en torno a Henry James, Álvaro Peláez y Zenia Yéhenes coords. (Ciudad de México: uam Cuajimalpa, 2018), 101.
} 
opacidad epistemológica que depende de la perspectiva; mientras más inmediata, más oscura". ${ }^{2}$ Además de la paradoja de la moral y la elección, ahora se agrega a los textos de James otra paradoja, la de la atención: estar en el caso implica la simplificación de los hechos y elementos del mismo, dando como resultado una comprensión incompleta de lo que sucede.

Al final de esta compilación, Esther Sánchez-Pardo analiza The Beast In The Jungle, expone la vida de un hombre encerrado en los modelos de relaciones interpersonales y sociales establecidos por su contexto. Si bien en los primeros artículos se aborda la manera en que los niños pierden su inocencia y se adentran en la búsqueda de su autonomía, en "Inquietante intimidad: The Beast In The Jungle y la reconfiguración del sujeto en relación" se exponen las consecuencias de no contemplar la falta de completitud epistemológica a la hora de interpretar el sistema social y ceder la poca autonomía que se puede tener por prestarle demasiada atención al caso y no a reflexionar sobre él.
Entre filosofia y literatura en torno a Henry James es una recapitulación de artículos donde cada uno expone un análisis profundo y exhaustivo de los escritos de James, sin dejar atrás detalles de la obra en cuestión. Esto conforma un libro donde la dificultad más visible radica en interpretar que los adultos de los últimos artículos alguna vez fueron niños, así se genera una trama externa que hila los seis artículos entre sí. La importancia de su contenido está en que, formalmente, no deja ningún concepto o trama sin desarrollar. Todas las nociones filosóficas y el desarrollo de las obras de James son ahondados con detenimiento. El lector puede aproximarse a esta compilación sin temor alguno, porque dentro de sus propósitos está exponer que todos comprenderán algo al relacionarlo con su experiencia. La lectura independiente de cada artículo permite tomar diferentes posturas ante varios conflictos morales y desde diversas perspectivas filosóficas. Ya sea que estemos interesados en cómo se perciben los niños a sí mismos

2 Carlos Mendiola Mejía, “La paradoja de la comprensión en La copa dorada de Henry James” en Entre flosofia y literatura en torno a Henry James, 143. 
y cómo crean su moral desde las acciones de quienes los rodean; la manera en que se toman las decisiones y qué involucran la nociones de libertad y representación; o la forma en que los juicios sobre otros y sus relaciones imposibilitan prestar atención a la reflexión sobre las propias acciones.

En conclusión, la obra coordinada por Álvaro Peláez y Zenia Yébenes ofrece un desarrollo y un análisis filosófico de la manera como James representa, desde su literatura, la complejidad ante la cual está expuesto el ser humano, y la importancia de no olvidar la injerencia que tiene la contingencia en todo lo relacionado con nuestras acciones y decisiones. Para algunos, concluir que no hay un principio moral previo a nuestra red de significado resulta desalentador; artículos como el de Carlos Mendiola Mejía permiten visibilizar que el que la compresión sea incompleta no es un rasgo negativo, sino una característica fundamental a contemplar al momento de hacer juicios, buscar tener mente propia y entablar relaciones interpersonales.

Nadie puede salir del sistema fenoménico en el cual se encuentra. El contexto determinará la manera en que se entablan las relaciones y concepciones de los hechos. Sin embargo, esto no quiere decir que no se deban cuestionar el entorno y los modelos sociales preestablecidos. La búsqueda por la libertad y la autonomía remite, en apariencia, a un intento por conocer y obtener la mayor cantidad de información posible antes de la toma de decisiones, incluso sabiendo que no hay distancia suficiente en la cual resguardase de imprevistos, engaños, secretos o malos entendidos. La experiencia consiste en la capacidad de pasar de lo evidente a lo que hay "entre líneas", es decir, aquello que parece invisible. Es esto lo que se debe interpretar para estar un poco más cerca de conocer algunos elementos del sistema de representación. Si lo que se desea es un acercamiento a las obras de Henry James, a las diferentes interpretaciones de su narración y características de escritura, y con ello reflexionar sobre la manera de relacionarse con la propia experiencia, este libro contiene los debates y cuestionamientos necesarios para conocer un poco mejor la oscuridad a la que siempre estamos expuestos. 